\title{
O PERFIL SOCIAL DOS JUİZES DE FORA DA CAPITANIA DO MATO GROSSO (SÉCULO XVIII): familias, matrimônios e carreiras
}

\author{
Gustavo Balbueno de Almeida*
}

\begin{abstract}
RESUMO: As instituições político/administrativa e também a justiça no período do Antigo Regime português vem sendo alvo de estudos há pouco mais de vinte anos no que se refere aos diversos pontos do Império português, reino ou ultramar, entre os séculos XV e XIX. Um deles é o juizado de fora, cargo de justiça proeminentemente português e que foi levado para outros pontos do Império, com o objetivo de cercear a atividade das elites locais exercendo a justiça e presidindo a câmara dos vereadores. Partindo da ideia de que, além das instituições, deve-se estudar também os homens que ocuparam os mesmos cargos, o objetivo desse artigo é apresentar um perfil social dos juízes de fora da capitania do Mato Grosso. Serão analisadas informações sobre suas vidas pessoais, além do desenrolar da carreira destes após cumprirem o tempo do cargo na capitania do Mato Grosso.

PALAVRAS-CHAVE: Juizado de fora; Perfil social; Capitania de Mato Grosso; Carreira.
\end{abstract}

\section{Juízes de fora social profile's of Mato Grosso capitaincy (18th century): familys, marriages and careers}

\begin{abstract}
The politic/administrative intitutions and also the justice in portuguese's Ancient Goverment has been studied in 20 years in reference to the several points of Portuguese Empire, land and overseas, between the XV e XIX centuries. On of them is the outside justice, a justice employment eminentment portugueses and which was taken to the whole empire with the objective of cutting the local elite activities doing the counciling job. Because of the study of the men whom occupied these employment is so important as the study of the institution this article presents a social profile of the judges of Mato Grosso. There will be analysed both their social and professional lives during their career in Mato Groso and after that.

KEY-WORDS: Judge; Social profile; Mato Grosso's capitaincy; Career.
\end{abstract}

\section{Perfil social de los juízes de fora de la capitania de Mato Grosso (siglo XVIII) : familias, matrimonios y carreras}

RESUMEN: Las instituciones políticas / administrativas y también la justicia en el Antiguo Régimen portugués es el objeto de estudios son poco más de veinte años con respecto a diferentes partes del imperio portugués, reino o en el extranjero, entre los siglos XV y XIX. Uno de ellos es el juizado de fora, trabajo prominente de la justicia portuguesa y fue tomada a otras partes del Imperio, con el objetivo de restringir la actividad de las élites locales en el ejercicio de la justicia y que preside el consejo de la ciudad . Partiendo de la idea de que, más allá de las instituciones también deben estudiar los hombres que ocupaban las mismas posiciones, el objetivo de este trabajo es presentar un perfil social de los juízes de fora de la capitanía de Mato Grosso. Se analizarán información acerca de su vida personal, además del desarrollo de la carrera de éstos después de completar el tiempo de carga de la capitanía de Mato Grosso .

PALABRAS CLAVE: Juízes de fora; Perfil social; Capitanía de Mato Grosso, Carrera.

\footnotetext{
*Mestre em História pela Universidade Federal da Grande Dourados. Atualmente é doutorando em História pelo Programa de Pós Graduação em História da Universidade Federal da Grande Dourados (PPGH/UFGD). Contato: Rodovia Dourados, Itahum, Km 12, Unidade II, Caixa Postal: 364, Cep: 79.804-970, Dourado-MS, Brasil. Email: gustavobalbueno@bol.com.br.
} 


\section{Introdução}

A administração da justiça no período colonial brasileiro é um tema que apenas há poucos anos tem chamado a atenção dos historiadores de uma forma mais intensa. $\mathrm{Na}$ historiografia clássica podemos atentar às visões antagônicas de Caio Prado Júnior e de Raimundo Faoro. O primeiro defende a existência de uma administração falha e uma máquina burocrática "monstruosa, emperrada e ineficiente". ${ }^{1}$ Já para Faoro, a sociedade americana não foi uma "criação consciente dos indivíduos", e sim uma criação imposta através das ordens régias. Para isso foi necessária a instalação de uma pesada máquina burocrática, trazida da Europa e implantada com sucesso na colônia. ${ }^{2}$ Nos início dos anos 1980, Laura de Mello e Souza confrontou as duas obras e propôs uma nova visão, que consideraria como certa as duas interpretações. Para ela, “engolfada em contradições, a administração mineira apresentou um movimento pendular entre a sujeição extrema ao Estado e a autonomia". ${ }^{3}$

Porém, apesar desses esforços isolados, as pesquisas dispostas a se dedicar de uma forma mais sistemática aos burocratas que agiam na administração da justiça colonial como objeto ganharam substância ao final da década de 1990. Elas devem, em grande parte, à obra do historiador português Antônio Manuel Hespanha e sua teoria corporativista do Estado Português. Utilizando-se de fontes do direito, teologia, filosofia, entre outras, o autor apresenta uma sociedade autorregulamentada, em que o rei era a "cabeça" de um corpo social e responsável pela harmonização dos demais membros. Dessa forma seria possível, então, realizar a justiça. ${ }^{4}$ Para isso, o rei necessitaria de instituições que cumpririam as suas funções, tanto no reino quanto no ultramar. São esses cargos e seus ocupantes que se tornaram objetos de estudos tanto por estudantes em programas de pós graduações quanto por pesquisadores já estabelecidos. $^{5}$

Outra referência essencial para os estudos sobre a burocracia portuguesa é a obra do historiador brasilianista Stuart Schwartz, Burocracia e sociedade colonial. Esse livro, lançado na década de 1970, pode ser considerado o marco inicial para o estudo da atuação dos magistrados em terras americanas. Segundo o autor, "para chegar a uma visão integral da operação do governo real no Brasil, é preciso comprrender tanto a burocracia quanto os burocratas". ${ }^{6}$ Em seu clássico estudo, que se dedica ao Tribunal da Relação da Bahia ele atesta que "foram os homens, não as leis, que tornaram a Relação uma instituição dinâmica". 7

Dessa forma, tomando por base as observações de Schwartz, o objetivo desse trabalho é apresentar algumas informações sobre os magistrados que ocuparam o cargo do juizado de fora na capitania do Mato Grosso entre os anos de 1750 e 1800. Afinal, para se entender a 
atuação dos oficiais de justiça do período do Antigo Regime, cumpre-se também conhecer suas trajetórias administrativas e pessoais. Entre elas os locais de nascimento, informações sobre suas famílias, nomeações para outros cargos em momentos posteriores à atuação na capitania do Mato Grosso.

Como recurso metodológico para a análise das questões referentes ao local de nascimento, identificação das famílias dos juízes de fora e as nomeações futuras, nos utilizaremos da prosopografia. Essa metodologia, para Lawrence Stone constitue-se na

investigação das características comuns de um grupo de atores na história por meio de um estudo coletivo de suas vidas. O método empregado constitui-se em estabelecer um universo a ser estudado e então investigar um conjunto de questões uniformes - a respeito de nascimento e morte, casamento e família, origens sociais e posição econômica herdada, lugar de residência, educação, tamanho e origem da riqueza pessoal, ocupação, religião, experiência em cargos e assim por diante ${ }^{8}$.

Para Nuno Camarinhas, a prosopografia visa a delimitação de um universo a ser estudado, em geral um grupo social, por meio da elaboração de um questionário a ser desenvolvido em relação a cada um dos indivíduos do grupo. $\mathrm{O}$ objetivo desse aporte metodológico é, em geral, o de desvendar a mobilidade social dos personagens, suas práticas e comportamentos. ${ }^{9}$

As fontes utilizadas encontram-se nos acervos do Arquivo Histórico Ultramarino (AHU), do Arquivo Público do Mato Grosso (APMT), além de dois documentos que encontramos no site do Arquivo Nacional da Torre do Tombo (ANTT). Também foram obtidos dados em obras historiográficas sobre a capitania, e obras de referência, como a de Augusto de Leverger ${ }^{10}$ e do Dicionário dos Desembargadores, de José Subtil ${ }^{11}$. Apesar de todos os esforços, ainda existem algumas lacunas que, no momento ainda é possivel preencher, principalmente por falta do acesso à documentação que se encontra no ANTT, situado em Lisboa. Porém, a partir das fontes até agora reunidas, já é possível determinar o início de um perfil social desses oficiais régios e contribuir para um maior entendimento da administração da justiça na fronteira oeste do Império português na segunda metade do século XVIII.

\section{O juizado de fora no Império Português}

O ofício de juiz de fora está associado à administração da justiça no termo da municipalidade e a sua criação remete ao período medieval. Stuart Schwartz ${ }^{12}$ aponta como ano exato de sua criação o de 1352, enquanto para Suely Cordeiro de Almeida a data exata seria 02/05/1349. ${ }^{13}$ Suas funções originais estavam relacionadas à execução dos testamentos 
no período da peste negra. Ainda de acordo com Suely Cordeiro, no período da criação do cargo, "os juízes de fora foram um instrumento da coroa que impediu que uma grande quantidade de terras e riquezas passasse para os eclesiásticos, ficando isentas de pagamento de impostos". ${ }^{14}$ No século XVI, principalmente a partir de 1550, os ocupantes do cargo ganharam o poder da presidência das câmaras municipais ${ }^{15}$ e sua popularização no reino se deu a partir da segunda metade do século XVII. ${ }^{16}$

Na América Portuguesa o juizado de fora foi criado pela primeira vez na cidade da Bahia, em 1696. Nuno Camarinhas faz uma relação completa das cidades e/ou vilas nos quais os cargos foram criados durante o século XVIII. Além da Bahia (1696), contamos com esse cargo em Pernambuco (1700) e Rio de Janeiro (1701), em um primeiro momento. Após essa primeira, o cargo é criado em “outros municípios menores, mas estratégicos do ponto de vista do comercio do ouro e dos diamantes": Santos (1713), Itú (1726), Ribeirão do Carmo (1731), Mato Grosso (1748), Maranhão (1753), Cachoeira (1758), Pará (1758), Cuiabá (1760), Paracatu do Príncipe (1799), Rio Verde (1799) e São Salvador do Campo dos Goitacazes (1802). ${ }^{17}$ Complementamos essa relação com a informação de que o juizado que foi criado no Mato Grosso $^{18}$, em 1748 foi extinto em 1758 para que se pudesse criar um em Cuiabá em 1760.

Outro ponto interessante na discussão de Camarinhas, diz respeito à afirmação de que os cargos de juízes de fora na América Portuguesa teriam sido criados em locais que fossem considerados estratégicos para o comércio de ouro e de diamantes. Essa afirmação vem corroborar o que aponta Maria Fernanda Bicalho:

[...] no caso das cidades marítimas mais importantes da América Portuguesa, uma das razões mais importantes para a criação do cargo de juiz de fora foi, sem duvida, a necessidade sentida pela Coroa, de intervir nas funções administrativas e financeiras - especificamente tributárias - das câmaras coloniais, para controlar os descaminhos e os possíveis prejuízos da Real Fazenda ${ }^{19}$.

No entanto, há que se destacar que a criação do cargo de juiz de fora não está relacionado apenas com questões financeiras e fiscais. Estudos de Maria Fernanda Bicalho e de outros pesquisadores afirmam que as câmaras municipais tiveram autonomia frente à corte nas vilas e cidades da América Portuguesa nos dois primeiros séculos de ocupação portuguesa. Apenas a partir do início do século XVIII, a Coroa sentiu necessidade de cercear as atividades dessas instituições e de seus representantes, fruto de uma política de maior centralização. Uma das formas encontradas foi a criação de alguns juizados de fora que, como presidente da câmara, viria a representar os interesses metropolitanos frente à população local. $^{20}$ 
Por outro lado, é sempre bom lembrar as afirmações de Antônio Manuel Hespanha, que mostra que, mesmo com essas tentativas por parte da coroa, o controle desses poderes locais não se realizava a contento. Isso porque apenas a presença dos agentes metropolitanos per si não significava que tal centralização se concretizava. No interior da municipalidade ainda haviam vários fatores a serem repeitados, como o direito consuetudinário, ou costumeiro, baseado na tradição, que se contrapunha ao direito; o poder delegado aos locais, quando estes assumiam os cargos públicos, como os tabelionatos, o de escrivão, entre outros, que os tornavam os guardiões da memória administrativa local. Sem contar os interesses dos próprios oficiais que, sendo mandados para aplicar de forma neutra a justiça régia acabavam por se envolver com a política e redes locais e tirar delas vantagens econômicas. ${ }^{21}$

O cargo de juiz de fora foi criado na fronteira oeste no ano de 1748, embora pedidos para sua criação na Vila do Cuiabá - até então única vila da futura capitania do Mato Grosso - existissem desde meados da década de 1730. Segundo Nauk Maria de Jesus, em 1735 ,o conde de Sarzedas havia solicitado o cargo para "melhor administrar a justiça das partes que se queixam, porque para ser assessor tinha que ser letrado de profissão". ${ }^{22}$ Em 1738, o intendente da Vila do Cuiabá encaminhou o pedido ao rei, devido a diversas irregularidades que estavam acontecendo na localidade. ${ }^{23}$ Apesar dos pedidos, o cargo só foi criado na capitania de Mato Grosso, no ano de 1748, juntamente com o de governador. Destinou-se ser Vila Bela, fundada pelo governador Antônio Rolim de Moura, no início de 1752, a capital.

$\mathrm{Na}$ tabela a seguir, apresenta-se a relação dos juízes de fora que atuaram nessa capitania, os anos de atuação de cada um, a vila de atuação - levando-se em conta que houve cargos tanto em Vila Bela, quanto em Vila do Cuiabá - e o ano em que efetuaram as leituras de bacharéis. Essas leituras constituíam em um teste realizado pelo Desembargo do Paço, a que submetiam todos os formados em Direito que se interessassem em trabalhar nos cargos letrados oferecidos pela Coroa. ${ }^{24}$ 
Tabela 1: Relação dos juízes de fora da capitania do Mato Grosso (1751-1799)

\begin{tabular}{|l|l|l|l|}
\hline Juiz de fora & Ano de atuação & Vila de atuação & Ano da leitura \\
\hline Teotonio da Silva Gusmão & $1752-1756$ & Vila Bela & 1741 \\
\hline Manuel Fangueiro Frausto & $1756-1759$ & Vila Bela & 1745 \\
\hline $\begin{array}{l}\text { Constantino José da Silva } \\
\text { Azevedo* }\end{array}$ & $1762-1766$ & Cuiabá & 1756 \\
\hline João Batista Duarte & $1766-1775$ & Cuiabá & 1754 \\
\hline José Carlos Pereira & $1775-1781$ & Cuiabá & 1771 \\
\hline Antônio Rodrigues Gaioso & $1781-1786$ & Cuiabá & 1778 \\
\hline Diogo de Toledo Lara Ordonhez & $1786-1792$ & Cuiabá & Ant. a 1784** \\
\hline Luiz Manoel de Moura Cabral*** & $1792-1799$ & Cuiabá & 1787 \\
\hline
\end{tabular}

Fontes: JESUS, Nauk Maria de. A administração da justiça. Op. cit. p, 181; LEVERGER, Augusto de. Apontamentos cronológicos da província de Mato Grosso. op. cit.; AMARAL, Luís; MATOS, Lourenço Correia de. Leitura de bacharéis - Índice dos processos. Lisboa: Guarda-mor, 2007[?], p. 33; SUBTIL, José. Dicionário dos desembargadores. op. cit. p, 108.

* Identificado no livro Leitura dos bacharéis como Constantino José da Silva, sem o seu último sobrenome. Porém, como o ano de sua leitura efetuou-se pouco tempo antes de o oficial assumir o cargo em Mato Grosso, acreditamos tratarem-se da mesma pessoa. In: AMARAL, Luís; MATOS, Lourenço Correia de. Leitura de bacharéis. Op. cit. p, 67.

** Não encontramos o ano de sua leitura. Encontramos, no Dicionário dos desembargadores a sua primeira indicação para um cargo como juiz de fora de Mato Grosso em 1784. In: SUBTIL, José. Dicionário dos desembargadores. op. cit. p, 108.

*** Encontramos na Leitura dos Bacharéis dois nomes idênticos, com exceção do último sobrenome, que consta em apenas um deles. Em decorrência disso, e também do ano de leitura, 1787, em comparação com o ano da leitura do outro nome, 1768, optamos por eleger o oficial com o nome completo. Será o Luiz Manuel de Moura encontrado pai do nosso Juiz de fora? In: AMARAL, Luís; MATOS, Lourenço Correia de. Leitura de bacharéis. Op. cit. p, 143.

Nos documentos consultados também encontramos uma informação sobre a nomeação de José Belarmino Crê para o cargo de juiz de fora. O nome desse magistrado é citado apenas em um documento com data de janeiro de 1778, como indicado para a Vila do Cuiabá, o que nos faz crer que esse oficial viria a substituir José Carlos Pereira. Por motivos que não se sabe, sua escolha foi preterida à de Antônio Rodrigues Gaioso, que atuou durante a primeira metade da década de $1780 .^{25}$ José Belarmino Crê fez sua leitura de bacharel em 1769 e, no ano de 1778, foi nomeado para o cargo de juiz de fora de Arronches em dezessete de outubro, onde tomou posse do cargo em vinte e seis de novembro do mesmo ano. O oficial foi também Corregedor em Abrantes a partir de 1783, e desembargador da Relação do Porto em 1806. Era descendente de irlandês por parte de pai e de lisboeta por parte de mãe. Nasceu por volta de 1736 ou 1737, o que indica uma entrada tardia na burocracia da coroa, já com mais de quarenta anos e casou desde 1768 com Joaquina Antônia de Faria Tagarro. ${ }^{26}$

A partir dessa apresentação do cargo de juiz de fora no Império Português e na capitania do Mato Grosso, analisaremos as informações no tocante às origens dos oficiais, as 
origens familiares e as nomeações futuras (quando houve) para outros cargos no interior do aparelho burocrático do Império português.

\section{Os juízes de fora na capitania do Mato Grosso: origens sociais, nomeações futuras}

Antes de iniciarmos as considerações sobre o perfil social dos juízes de fora da capitania, é importante a realização de uma pequena discussão acerca do envolvimento dos juízes de fora com as elites. De acordo com Maria Fernanda Bicalho há na historiografia rumos opostos quando se trata de medir a importância desses oficiais como elemento desagregador das elites locais. Segundo a autora,

Se alguns estudos monográficos sobre as instituições concelhias portuguesas levam a crer que este funcionário [juiz de fora] representou de fato um elemento de enfraquecimento das estruturas locais, outros autores, debruçados sobre a dinâmica político-administrativo de outros concelhos no reino, afirmam que a presença de um oficial letrado nomeado pela coroa para agir como braço do poder central nos remotos rincões da monarquia portuguesa não poderia ter contrariado as tendências oligárquicas do poder municipal. Pelo contrário, ele as teria reforçado. ${ }^{27}$

Em relação a essa questão, entende-se que havia um envolvimento desses oficiais com as elites locais. Para o caso baiano, Avanete Sousa argumenta que a relação dos juízes de fora com as elites locais de Salvador "não provocou o hipotético distanciamento dos dramas e interesses cotidianos da cidade". ${ }^{28}$ Stuart Schwartz, em seu estudo sobre o Tribunal da Relação da Bahia, elaborou o clássico conceito do "abrasileiramento da burocracia". Segundo esse autor "a sociedade colonial mostrou extraordinária capacidade de 'abrasileirar' os burocratas", no sentido de "integrá-los ao sistema existente de poder e patronagem. Os estímulos oferecidos por grupos e indivíduos da colônia e o desejo dos magistrados puseram em movimento o processo de interpenetração". Por isso adverte o autor que "o impacto da magistratura na sociedade colonial precisa ser visto não apenas em termos de suas ações profissionais, mas à luz do estilo de vida e das motivações pessoais dos magistrados e das reações ou iniciativas de certos elementos da população colonial em relação à ela" ${ }^{29}$ Portanto, entendendo que é impossível aos magistrados não se envolverem com as elites locais, buscaremos montar o perfil social desses magistrados que atuaram na capitania do Mato Grosso na segunda metade do século XVIII.

Em relação aos locais de origem dos oficiais, foi possível determinar alguns deles. Teotônio da Silva Gusmão, Diogo de Toledo Lara Ordonhez, José Carlos Pereira e Antônio Rodrigues Gaioso - ou seja, metade dos juízes estudados - eram naturais da América Portuguesa. Esse fato chama a atenção, afinal, isso significa que os oficiais régios não apenas se adaptavam às sociedades locais, mas também provinham dela. Isabele Mello destaca o 
aumento no número de estudantes brasileiros na Universidade de Coimbra a partir da década de $1720^{30}$, o que acabou resultando, consequentemente, em um maior número de nomeações aos provenientes da América Portuguesa.

Teotônio Gusmão era da capitania de São Paulo, natural da Vila de Santos, assim como a maioria de sua família e de seus tios famosos, Alexandre de Gusmão e Bartolomeu de Gusmão. Era filho de Maria Gomes de Gusmão, também natural da Vila de Santos, e de Geraldo da Silva, natural de Vila do Frades, distrito de Madalena. Não foi possível identificar a data de seu nascimento. ${ }^{31}$

Lara Ordonhez, quinto juiz de fora da Vila do Cuiabá, também era da capitania de São Paulo, natural da cidade de mesmo nome e tinha, quando assumiu o cargo na Vila do Cuiabá, 35 anos. Nasceu em 1758, e era filho do mestre de campo Agostinho Delgado de Arouche e Maria Teresa do Araújo. ${ }^{32}$ Tinha parentes poderosos nas capitanias de São Paulo, Rio de Janeiro, Minas Gerais, Lisboa e na capitania de Mato Grosso. ${ }^{33}$ Essa informação não deixa de chamar a atenção, considerando-se que consta na historiografia que um dos preceitos básicos para a escolha de um juiz de fora era que ele não tivesse vínculos, comerciais ou de parentesco, no local de atuação. ${ }^{34}$ Afinal, esse oficial era indicado para as vilas e cidades em substituição ao juiz ordinário, um membro da elite local, que poderia se utilizar de seu cargo para beneficiar suas parcialidades, ou para aderir às possíveis pressões que poderiam receber de outros poderosos locais. ${ }^{35}$ No caso de Ordonhez, seus vínculos com a capitania de São Paulo continuariam por toda sua vida, visto que recebeu uma carta de confirmação de sesmaria de uma légua de testada com três de sertão na capitania de São Paulo em 1799, e uma carta de sesmaria de terras citas na paragem do Rio Pardo, caminho de Goiás, em 1802. ${ }^{36}$

Antônio Rodrigues Gaioso, o sexto juiz de fora da capitania, era natural da cidade de Salvador, na Bahia. Graças à sua leitura de bacharel, disponível no site da Torre do Tombo, pudemos ter acesso à informações não encontradas em outros acervos. Era filho de Alexandre Soares Rodrigues da Silva e de Maria da Conceição, tendo por avós paternos João Soares Jorge e Joana Maria, e maternos Sebastiaão da Cunha de Araújo e Maria da Cruz. Tanto o pai quanto o avô paterno haviam exercido o cargo de vereador na mesma cidade, o que indica que Antônio Rodrigues Gaioso fazia parte de uma importante família da cidade. No momento da leitura, realizada em vinte e três de agosto de 1778, ano de sua conclusão de curso, o futuro juiz tinha vinte e seis anos, o que indica que chegou à Vila de Cuiabá com a idade de vinte e nove anos. $^{37}$

O juiz que nasceu no Brasil sobre quem menos temos informação é José Carlos Pereira, antecessor de Antônio Rodrigues Gaioso. Em uma carta ao governador Luís de 
Albuquerque Melo Pereira e Cáceres, ele comenta sobre sua vila de nascimento como sendo Cachoeiro, na Bahia. ${ }^{38}$ Afora isso, não contamos com mais informação nenhuma sobre esse magistrado.

Conforme pudemos apurar, os outros juízes de fora eram do reino. Manuel Fangueiro Frausto era de Lisboa, local onde deixou família, cujos detalhes serão apresentados logo a seguir. ${ }^{39}$ João Batista Duarte era natural da Vila de Guimarães. ${ }^{40}$ Luís Manoel de Moura Cabral nasceu em 1762 ou 1763, e era natural do "lugar de Pombal", na comarca de Moncorvo. Filho de Manuel de Escobar e Moura Cabral e de Rosa Maria Azevedo, neto paterno de Vicente de Moura e de Maria de Escobar, e neto materno de João de Azevedo e de Catarina Luís Cardenha. Nas observações sobre sua origem, apresentada no Dicionário dos desembargadores, consta ainda que

Os pais e avós são naturais do lugar de Pombal do Concelho de alfândega da Fé. O defunto pai era bacharel formado na Universidade de Coimbra com grau de Doutor e advogou no concelho de alfândega da Fé. Os pais e avós viviam do rendimento das suas fazendas, sendo os avós dos lavradores principais do lugar de Pombal. O habilitante é, a data de 1788, solteiro e morador no lugar de Pombal. O habilitante é bom estudante. ${ }^{41}$

Constantino José da Silva Azevedo nasceu na cidade de Braga. Era filho do capitão João da Silva e Luiza da Silva, neto por parte paterna de Manoel Lourenço da Silva e Maria Fonseca e, por parte materna, de Francisco Ribeiro Gago e Elena da Silva. Como o documento encontrado diz respeito ao processo para o recebimento da Ordem de Cristo, e não a leitura de bacharel (ainda que ambos os documentos contém informações semelhantes para a obtenção desse tipo de informação), este foi produzido num período posterior ao tempo em que ele exerceu o cargo de juiz de fora em Cuiabá. Nessa ocasião, no ano de 1772, o requerente constava com a idade de aproximadamente quarenta e cinco anos anos, o que indica que, quando chegou ao Cuiabá tinha aproximadamente trinta e cinco anos anos. ${ }^{42}$

A análise da idade dos juízes de fora a que tivemos acesso, nos permite relativizar a afirmação de Suely Almeida ${ }^{43}$, que atestou a média de idade para os juízes de fora que assumiam o cargo de vinte e seis a vinte e oito anos. Afinal, dos quatro juízes a que tivemos acesso às informações, três deles assumiram o cargo com vinte e nove anos ou mais, enquanto apenas um contava com a idade de vinte e oito anos.

A seguir montamos uma tabela para uma melhor observação dos locais de nascimento dos juízes de fora que serviram na capitania do Mato Grosso na segunda metade do século XVIII. 
Tabela 2: Local de origem dos juízes de fora que exerceram cargos na capitania de Mato Grosso.

\begin{tabular}{|c|c|}
\hline Portugal & América Portuguesa \\
\hline 4 & 4 \\
\hline
\end{tabular}

Fonte: Ver notas de rodapé 27-38.

Tabela 3: Cidade/Vila de nascimento dos juízes de fora

\begin{tabular}{|l|l|l|l|l|l|l|l|}
\hline Santos & Lisboa & Braga & Guimarães & Cachoeiro & Salvador & $\begin{array}{l}\text { São } \\
\text { Paulo }\end{array}$ & Pombal \\
\hline $\mathbf{1}$ & $\mathbf{1}$ & $\mathbf{1}$ & $\mathbf{1}$ & $\mathbf{1}$ & $\mathbf{1}$ & $\mathbf{1}$ & $\mathbf{1}$ \\
\hline
\end{tabular}

Fonte: Ver notas de rodapé 27-38.

No que se refere ao estado civil dos oficiais registre-se que, daqueles que contraíram matrimônio em período anterior à sua nomeação para o cargo, tem-se notícias apenas de Manuel Fangueiro Frausto. O oficial foi casado com Antônia Joaquina Lobato e teve dois filhos, Estevão Fangueiro de Frausto e Athaíde José Fangueiro de Frausto, que residiam, no reino. A esposa e os filhos foram considerados seus herdeiros após sua morte, em Vila Bela, na década de 1760 . O oficial também tinha como dependentes sua sogra e duas cunhadas. ${ }^{44}$

No período em que foi nomeado para o Mato Grosso, a família já era alvo de preocupação do oficial. Em requerimento ao rei, ele pediu que fosse descontado mensalmente o valor de 20 mil réis de seu soldo para que seus dependentes "se possam sustentar com a decência de que necessitam". De acordo com o mesmo documento, essa prática era comum a alguns ministros e a todos os oficiais militares que foram para o Mato Grosso. ${ }^{45}$

Como não bastasse a dificuldade financeira de sua família no reino, ela ainda sofreria mais um revés quando, em 1755, um terremoto destruiu a cidade de Lisboa. ${ }^{46}$ Por coincidência, Manuel Frausto foi incumbido de reunir as doações que seriam feitas pela população de Vila Bela da Santíssima Trindade para a reconstrução da capital do reino. A quantia acumulada pelo juiz de fora foi de 1953 mil oitavas, três quartos e nove grãos de ouro. Segundo Lacerda (2011: 274-276), a capitania ficaria responsável pela doação de 50 mil cruzados, que seria cobrada através do imposto de diversos produtos. A Câmara da Vila do Cuiabá contribuiu com a quantia de 16.000 oitavas. ${ }^{47}$ A ajuda seria dada até o ano de 1769 , porém, uma cobrança especial se manteve até o ano de 1799 para a reconstrução do Palácio da Ajuda. Em 1800 foi criado um novo imposto pelo governador Caetano Pinto de Miranda Montenegro, dessa vez para a reedificação do Palácio Real. As contribuições, nas diversas partes do Brasil, só terminariam em 1822, com a independência em relação à Portugal. 
Ao fim de seu mandato como juiz de fora, em 1759, Manuel Fangueiro Frausto foi nomeado o novo ouvidor da Comarca do Mato Grosso, após a recusa de Teotônio da Silva Gusmão, o juiz antecessor à Fangueiro Frausto, para o cargo. Após a nomeação, o oficial enviou uma carta ao Secretário da Marinha e Ultramar, Martinho de Melo e Castro, atestando que, não obstante ter assumido o cargo, reconhecia estar "na esperança de retirar-me a acudir o memorável estado que minha mulher e filhos estão experimentando por causa do terrível terremoto". ${ }^{48}$ Tudo indica que o oficial não pôde amparar sua família e que possivelmente não a tenha visto mais. Em documento anterior a 1770, têm-se notícia de sua morte na vilacapital. $^{49}$

As informações mencionadas nos ajudam a perceber aspectos da vida privada de um oficial pobre, com uma família numerosa para sustentar, aparentemente, apenas com suas rendas. Pelo menos esse é o motivo encontrado pelo governador Antônio Rolim de Moura, para explicar que "quando [Manuel Fangueiro Frausto] chegou logo a estas minas se deixou cair em algumas coisas em que mostrou bastante ambição". 50

Estaria esse envolvimento relacionado a atividades comerciais? $\mathrm{Ou}$, quem sabe, a alguma atividade relacionada à extração de ouro? Não se pode esquecer que, com essa declaração, o governador poderia estar pretendendo proteger o magistrado de algumas ações a que ele também estivesse envolvido. Afinal, após discorrer sobre a impossibilidade da existência de um ministro completo, especialmente os ministros da América "que tem tanta ocasião e facilidade de serem maus", pede que Manuel Fagueiro Frausto fosse mantido no cargo até o fim de seu mandato como governador: "se há de vir algum que me perturbe, antes quero sofrer a este". 51

Ao tratar dos desembargadores da Relação da Bahia, Stuart Schwartz menciona a existência da venialidade e das condutas ilegais desses oficiais de justiça, afirmações que também podem ser extendidas aos oficiais de menor importância, como os ouvidores e os juízes de fora. Segundo esse autor, “a crescente burocratização do Império e o contínuo acúmulo de obrigação e poderes pelos desembargadores criavam oportunidades de corrupção cada vez mais numerosas". ${ }^{2}$ Dessa maneira, para Schwartz, as maneiras mais graves de corrupção seriam aquelas que "envolviam trocas de favores e recompensas entre um magistrados e outro membro qualquer da sociedade" em que eram considerados numerosos critérios "pessoais, classistas, monetários e atributivos" para a prática da corrupção. ${ }^{53}$ Ou seja, as ações de Manuel Fangueiro Frausto mencionadas pelo governador podem envolver qualquer um desses padrões acima descritos. Infelizmente a documentação não permite que tais ações sejam exploradas mais a fundo. 
Ainda que demos sorte em conseguir construir minimamente aspectos da vida privada de Fangueiro Frausto, infelizmente não se pode dizer o mesmo para os outros oficiais. Laura de Mello e Souza analisou a documentação relativa à vida privada do Conde de Assumar, governador das minas no início do século XVIII e, posteriormente, vice-rei da índia e salienta a dificuldade em se encontrar passagens sobre as questões privadas dos governantes das possessões ultramarinas. ${ }^{54}$ Para os juízes de fora da capitania do Mato Grosso da segunda metade do século XVIII, com exceção do caso já apresentado, temos pequenas informações sobre alguns dos oficiais. Sabemos que Antônio Rodrigues Gaioso e Luís Manoel Moura Cabral eram solteiros no momento da realização da Leitura de Bacharel. ${ }^{55} \mathrm{O}$ último, em carta de 1790 ao governador da capitania do Mato Grosso, João de Albuquerque Melo Pereira e Cáceres, quando ainda se encontrava na cidade do Rio de Janeiro rumo à Cuiabá, mencionou a companhia de sua "mulher". ${ }^{56}$ Porém, é a única informação que temos sobre o assunto (atentemos que o juiz não usa a expressão "esposa"). Constantino José da Silva Azevedo também era solteiro, já num período posterior à sua estada na Vila do Cuiabá. ${ }^{57}$ Curiosamente, uma sindicância realizada após seu mandato, chamou a atenção para a existência de uma suposta mulher que ele teria "roubado" de um comerciante durante o tempo em que passou por Santos rumo à Cuiabá. Ele teria instalado-a em uma casa na parte nova da Vila e seu caso era "público e notório" para a população. ${ }^{58}$

Quanto aos cargos posteriores ocupados pelos juízes de fora da capitania de Mato Grosso, pode-se também fazer algumas considerações. Teotônio da Silva Gusmão recusou o cargo de ouvidor de Vila Bela, e Manuel Fangueiro Frausto assumiu a ouvioria na mesma capitania em 1759. ${ }^{59}$ Alguns juízes de fora da vila de Cuiabá, todos no último quartel do século XVIII, também assumiram outros cargos da hierarquia letrada do Império Português.

O juiz de fora da Vila do Cuiabá, José Carlos Pereira (1775-1781) foi nomeado para a Intendência do ouro de Goiás. ${ }^{60}$ Antônio Rodrigues Gaioso, sucessor de José Carlos Pereira, a despeito de seu envolvimento em diversos conflitos que resultaram em um atentado contra sua vida e em uma sindicância para avaliar o seu governo, foi nomeado para o Tribunal da Relação do Rio de Janeiro, com posse na Relação do Porto, em 07/09/1789. Possivelmente esse tenha sido o seu último cargo. ${ }^{61}$

Diogo de Toledo Lara Ordonhez foi nomeado para a Intendência do ouro do Rio de Janeiro, em 1789, enquanto cumpria o cargo de juiz de fora em Cuiabá. Provavelmente cumpriu o cargo após deixar a capitania do Mato Grosso já que, em 1798, pediu provisão para o vencimento do salário de intendente, juntamente com a recondução ao cargo. Em 1801 recebeu o lugar de desembargador da Relação do Porto. ${ }^{62}$ Porém, antes disso, no ano de 1794 
- provavelmente quando o oficial já estava atuando como intendente no Rio de Janeiro - ele havia sido nomeado para o cargo de juiz de fora de Coimbra, no reino. Por algum motivo, o oficial não foi à corte e atuou por mais alguns anos na Intendência do ouro. ${ }^{63} \mathrm{Na}$ década de 1820, Diogo de Toledo Lara Ordonhez foi identificado como conselheiro do Conselho da Fazenda do Brasil. ${ }^{64}$ De acordo com Renata Malcher de Araújo, ele ainda foi fiscal das mercês e, depois da Independência, foi deputado pela província de São Paulo. Morreu no Rio de Janeiro, em $1826 .{ }^{65}$

Luís Manoel de Moura Cabral foi o mais bem sucedido juiz de fora entre os profissionais que atuaram no juizado de fora da capitania do Mato Grosso no século XVIII. Seu currículo apresenta sete cargos, assumidos ora na América Portuguesa, ora no Reino. Após os sete anos em que serviu na Vila de Cuiabá, de 1792 a 1799, foi nomeado como ouvidor do Ceará por três anos (1802-1805). A partir de 1811, serviria como Desembargador da Relação da Bahia e, concomitantemente, como Intendente do ouro da Bahia, de 1812 até o ano de 1817. Em dezessete de julho de 1822, tornou-se Desembargador da Casa da Suplicação até 15/04/1825. Em seguida, assumiu como Conservador-geral da junta de administração do tabaco, em vinte de maio do mesmo ano. Em 1826 recebeu a carta de título de Conselheiro e, em março de 1827 , de fidalgo cavaleiro. ${ }^{66}$

Constantino José da Silva Azevedo (1762-1766), por sua vez, após cumprir o seu mandato, foi para a Corte se defender das acusações feitas a ele em sua sindicância, conforme mencionado acima. ${ }^{67}$ É certo que manchas em sua ficha poderiam impedir futuras nomeações, mas não foi o que aconteceu. No ano de 1772 o magistrado foi nomeado para o cargo de ouvidor nas Ilhas de São Tomé e Príncipe. Não podemos afirmar se, de fato, assumiu o cargo. A última informação que temos do oficial é a de que estava prestes a embarcar para o local indicado. ${ }^{68}$

Por último, o caso mais curioso de todos os apresentados, o de João Batista Duarte (1766-1775) que, após o fim de seu mandato, tornou-se morador na Vila do Cuiabá, local onde atuou, tornando-se um dos principais "homens bons" do local. Sabe-se que o ex-juiz de fora chegou a se indispor com um de seus sucessores, Antonio Rodrigues Gaioso, na década de 1780. Não se tem informações sobre qual a profissão assumida por ele, nem os motivos que o levaram continuar na vila, o que necessitará de pesquisas futuras. ${ }^{69}$ Carlos Alberto Rosa atesta que o ex-oficial possuía uma chácara no "Largo da Cruz das Almas" e um forno de cal em frente à Capela São Gonçalo. ${ }^{70}$ 


\section{As residências}

Normalmente, o que definia o futuro profissional dos oficiais era a residência. Segundo Isabela de Matos Pereira Mello, a residência era "o exame, ou informação que se tirava dos procedimentos e da atuação dos funcionários da administração. O objetivo das residências era averiguar os procedimentos dos funcionários quando do exercício de seus ofícios na administração". Esse processo, portanto, abria à população das localidades a possibilidade da abertura de queixas contra os oficiais ao fim do exercício de seu mandato. Continua a autora: "a convocação de testemunhas para depor contra ou a favor do magistrado representava no mínimo um ato simbólico de julgamento de suas atividades". ${ }^{71}$

As residências dos juízes de fora normalmente deveriam ser tiradas pelo ouvidor da comarca. Alguns juízes de fora da Vila do Cuiabá, entretanto, tiveram suas residências tiradas pelos seus sucessores. Constantino José da Silva Azevedo (1762-1766), o primeiro juiz desta vila, teve grandes dificuldades para que tirassem sua residência. Como essa prática ainda não era comum, João Batista Duarte (1766-1775), seu sucessor, não tirou a residência de seu antecessor. A distância entre a Vila do Cuiabá e Vila Bela, onde se encontrava a ouvidoria, era de 200 léguas e impossibilitava constantes viagens do ouvidor para Cuiabá. O magistrado, então, teve de ficar à espera de alguma decisão sobre o seu futuro e sua residência foi tirada apenas em 1771, pelo ouvidor Miguel Pereira Pinto. ${ }^{72}$

Como Constantino José de Azevedo se envolveu em conflitos com parcelas da sociedade cuiabana, e pairava sobre ele suspeitas de cobranças indevidas, pode-se problematizar a demora na tirada de sua residência. Ernest Pijning, ao analisar casos de contrabando na América Portuguesa, argumenta que a qualidade dos "status" do criminoso era levado em conta para a indicação da pena. Nesse sentido, quanto mais qualidades de nobreza tivesse o oficial, mais chances ele tinha de evitar ser condenado. ${ }^{73}$ Portanto, a demora na tirada da residência de Constantino José Silva Azevedo, que se deu quatro anos após o fim de seu mandato, pode ser entendida como uma maneira encontrada para livrá-lo das suas culpas. $^{74}$

Vale lembrar que, salvo exceções, sem a tirada da residência de um juiz de fora, o cargo não poderia ser ocupado pelo próximo oficial, o que forçava o juiz de fora a se manter em atividade no cargo. Em decorrência disso, na lei régia de 27/11/1764, enviada para o governador da capitania de Mato Grosso, João Pedro da Câmara, ficou decidido que os governadores teriam o poder de dar posse aos novos juízes de fora, mesmo antes que se tirasse a residência do oficial anterior. O motivo para essa decisão era uma tentativa de evitar 
os abusos cometidos pelos oficiais de justiça quando continuavam por mais tempo no cargo que os três anos habituais". ${ }^{75}$ A conjuntura política portuguesa a partir da subida de D. José I ao trono, em 1751, e a influência do Marquês de Pombal nesse governo, apresentou a adoção de medidas, por parte da Coroa, que possibilitasse uma maior centralização do governo metropolitano em relação às elites locais da América. ${ }^{76}$ Esse poder que foi dado ao governador para dar a posse aos juízes de fora, mesmo que o antecessor não tivesse a residência tirada, representava uma estratégia da Coroa em limitar o tempo de mandato dos oficiais ao máximo, afim de que os laços desses com as elites durassem o menor tempo possível. Utilizando-se dessa ordem, o governador João Pedro da Câmara fez "logo dar posse ao bacharel João Batista Duarte no lugar de juiz de fora da Vila do Cuiabá, em que foi provido por Vossa Majestade, sem embargo de não se ter tirado residência ao seu antecessor". 77

De fato, entre os juízes de fora que atuaram na capitania, alguns deles ultrapassaram (e muito) o tempo de permanência na Vila de Cuiabá para além dos três anos previstos. Destacamos o próprio João Batista Duarte (1767-1775) e Luís Manoel de Moura Cabral (1792-1799), que se manteviram por mais de oito anos no cargo. Já no século XIX, período não abarcado nesse trabalho, o juiz de fora Antônio José de Carvalho Chaves se manteve no cargo da Vila do Cuiabá pelos mesmos oito anos, entre 1813 e 1821.

Também em diversos outros pontos do Império houveram ocasiões em que juízes de fora permaneceram no cargo por quase dez anos. Em relação ao ocorrido na Bahia, no século XVIII, Avanete Pereira Sousa ${ }^{78}$ apresenta a hipótese de que a transposição do tempo de três anos previsto pelas Ordenações Filipinas pode ser explicado pela dificuldade em prover oficiais nos cargos. De acordo com a autora, "por questões particulares, nem todos os magistrados régios se dispunham a servir em terras distantes". O tempo médio de atuação no juizado de fora em Mato Grosso foi de pouco mais de cinco anos e meio. Os oficiais, José Carlos Pereira (1775-1781) e Diogo de Toledo Lara Ordonhez (1786-1791), após os três anos de mandato iniciais, contaram com mais três anos - a chamada "recondução" - em atendimento aos pedidos dos vereadores em exercício para que permanecessem no cargo. ${ }^{79}$

Esse artigo é o resultado parcial de uma pesquisa que ainda está em andamento. A consulta a outros arquivos como, por exemplo, o Arquivo Nacional da Torre do Tombo (ANTT), em Lisboa, certamente permitirá análises mais completas sobre o perfil sociais dos juízes de fora que atuaram na capitania do Mato Grosso. Por ora cabe destacar a necessidade de aprofundar as pesquisas em torno das origens sociais desses ministros régios, não só para o Mato Grosso, mas para todo o Império Português. Apenas dessa maneira será possível 
entender as lógicas do recrutamento dos oficiais régios e os limites da importância desse grupo social para a manutenção das colônias para Portugal. Por fim, ressaltamos a existência do envolvimento dos oficiais nomeados para a capitania com as elites locais, como podemos observar ao longo do texto. Ainda que a concepção do cargo de juiz de fora remetesse à neutralidade, em diversos momentos apontados, como a acusação contra Constanino José da Silva Azevedo no momento de sua residência, ou a carta enviada pelos vereadores para a recondução dos juízes José Carlos Pereira e Diogo Lara Ordonhez, apontam indícios de que havia participação dos oficiais de justiça em causas locais.

\section{Notas}

${ }^{1}$ PRADO JR. Caio. Formação do Brasil Contemporâneo. $17^{\circ}$ ed. São Paulo: Brasiliense, 1981 , p. 333
2 FAORO, Raymundo. Os donos do poder. Formação do patronato político brasileiro. $2^{\circ}$ ed. São Paulo: Ed.
Globo, 1975, p. 175 .
${ }^{3}$ SOUZA, Laura de Mello e. Desclassificados do ouro: a pobreza mineira no século XVIII. $3^{\circ}$ ed. Rio de Janeiro: Graal, 1986, p. 97.

${ }^{4}$ HESPANHA, Antônio Manuel; XAVIER, Ângelo Barreto. A representação da sociedade e do poder. In: HESPANHA, Antônio Manuel (cord.); MATTOSO, José (org.) História de Portugal: O Antigo Regime. Lisboa, Editorial Estampa, 1993, vol 4, p. 123.

${ }^{5}$ Apenas à guisa de apresentação, ver: SOUZA, Débora Cazelato de. Administração e poder local: a câmara de Mariana e seus juízes de fora (1730-1777). Dissertação (Mestrado em História). UFOP, Mariana, 2011; PEGORARO, Jonas Wilson. Ouvidores régios e centralização jurídico-administrativo na América portuguesa: a comarca de Paranaguá (1723-1812). 2007. 112 f. Dissertação (Mestrado em História). UFPR, Curitiba; MELLO, Isabela de Matos Pereira. Magistrados a serviço do rei: a administração da justiça e os ouvidores gerais na comarca do Rio de Janeiro (1710-1790). Tese (Doutoramento em História), UFF, Niterói, 2013. JESUS, Nauk Maria de. A administração da justiça: Ouvidores e regentes na fronteira oeste da América portuguesa. In GUEDES, Roberto (org.) Dinâmica Imperial no Antigo Regime Português. Escravidão, governos, fronteiras, poderes, legados. Rio de Janeiro: MAUAD X, 2011.

${ }^{6}$ SCHWARTZ, Stuart. Burocracia e sociedade no Brasil colonial, São Paulo: Companhia das letras, 2011.

${ }^{7}$ Idem, Ibidem, p. 73.

${ }^{8}$ STONE, Lawrence. Prosopografia. In.: Revista de Sociologia e Política. V.19, no 39. Curitiba: Junho 2011. Disponível em:

http://www.scielo.br/scielo.php?pid=S0104-44782011000200009\&script=sci_arttext. Acessado dia 06/11/2015.

${ }^{9}$ CAMARINHAS, Nuno. Juízes e administração da justiça no Antigo Regime. Portugal e o império colonial, séculos XVII e XVIII. Lousã: Fundação Calouste Gulbekian, 2010, p. 25.

${ }^{10}$ LEVERGER, Augusto de. Apontamentos cronológicos da província de Mato Grosso. Cuiabá:IHGMT, 2001.

${ }^{11}$ SUBTIL, José. Dicionário dos desembargadores (1640-1834). Lisboa: EDIUAL, 2010.

${ }^{12}$ SCHWARTZ, Stuart. Burocracia e sociedade no Brasil colonial, op. cit. p, 29.

${ }^{13}$ ALMEIDA, Suely Creusa Cordeiro. As peripécias do magistrado: Juízes de fora e um cotidiano nada tranquilo entre Recife e Olinda. Mneme - Revista de Humanidades - UFRN. Vol. 9, n24, set/out 2008, p. 1. Disponível em: www.cerescaico.ufrn.br/mneme/anais. Acesso em: 21/02/2011

${ }^{14}$ Idem. Ibidem, p. 1.

15 BOXER, Charles. O Império Ultramarino Português (1415-1825). São Paulo: Companhia das letras, $3^{\circ}$ reimpressão 2002, p. 288.

${ }^{16}$ Nesse sentido ver: MONTEIRO, Nuno Gonçalo. As comunidades e os concelhos. In: HESPANHA, Antonio. M; MATTOSO, José. História de Portugal - o Antigo Regime (1620-1807), volume IV. Lisboa: Editorial Estampa, 1993.; Antônio Manuel Hespanha afirma que, até o século XVII, havia a presença de juízes de fora em apenas em $8 \%$ das terras portuguesas. In: HESPANHA, Antônio Manuel. Às vésperas do Leviathan. Instituições e poder político, Portugal, séc. XVII. Coimbra: Livraria Almedina, 1994, p. 172. Nuno Camarinhas salienta que 
"Os lugares de juiz de fora na metrópole conhecerão um crescimento de mais de $40 \%$ durante o século XVII e XVIII”. In: CAMARINHAS, Nuno. Juízes e administração da justiça no Antigo Regime. Op. cit. p, 9.

${ }^{17}$ CAMARINHAS, Nuno. Juízes e administração da justiça no Antigo Regime. Op. cit. p, 123.

${ }^{18}$ Vale lembrar que o cargo criado em Mato Grosso em 1748 se refere ao de Vila Bela da Santíssima Trindade, que também era conhecida como Vila de Mato Grosso. Quando da criação do juizado de fora no distrito de Cuiabá, ele ficou estabelecido na vila de mesmo nome.

${ }^{19}$ BICALHO, Maria Fernanda. A cidade e o império - O Rio de Janeiro no séc. XVIII. Rio de Janeiro. Civilização Brasileira, 2003, p. 349.

${ }^{20}$ Para um maior conhecimento sobre as câmaras municipais ver: BICALHO, Maria Fernanda. As câmaras municipais no Império português: o exemplo do Rio de Janeiro. Revista Brasileira de História, vol. 18. ${ }^{\circ} 36$. São Paulo, 1998. Disponível em: http://www.scielo.br/scielo.php?pid=S010201881998000200011\&script=sci_arttext. Acessado dia: 1310512015.. Diversos trabalhos sobre as câmaras municipais podem ser elencados. Entre eles: SOUSA, Avanete Pereira Poder local, cidade e atividades econômicas. op. cit.; BICALHO, Maria Fernanda. As câmaras ultramarinas e o governo do Império. In: BICALHO, Maria Fernanda; FRAGOSO, João; Gouvêa, Maria de Fátima (Orgs.). O antigo regime nos trópicos: a dinâmica imperial portuguesa (séculos XVI-XVII). Rio de Janeiro. Civilização brasileira, 2010.; PUNTONI (2009). Para as câmaras municipais no reino ver: MONTEIRO, Nuno Gonçalo. As comunidades e os concelhos. Op. cit.

${ }^{21}$ Uma boa síntese dessas idéias encontra-se em: HESPANHA, Antônio Manuel. Antigo Regime nos trópicos? Um debate sobre o modelo político do império colonial português. In: FRAGOSO, João; GOUVEA, Maria de Fátima (orgs.) Na Trama das redes. Política e negócios no Império Português, séculos XVI-XVIII. Rio de Janeiro: Civilização Brasileira, 2010.

22 JESUS, Nauk Maria de. Na trama dos conflitos: a administração na fronteira oeste da América portuguesa(1719-1778). Tese (Doutoramento em História). UFF, Rio de Janeiro, 2006, p. 193.

${ }^{23}$ Idem. Ibidem, p. 196.

${ }^{24}$ Stuart Schwartz analisa minunciosamente o processo da Leitura dos bacharéis. Ele consistia em uma pesquisa para que ficasse provada a "pureza de sangue e de mãos" dos candidatos. Para isso era mandado ao juiz da localidade de nascimento dos pais e avós do futuro oficial uma ordem para que se pesquisasse a fundo os antepassados desses e seus antecedentes, e se certificasse que não havia sangue mouro, negro ou judeu no passado da família. A ocupação profissionais dos pais e avós também era ponto importante, já que apenas os descendentes daqueles que não trabalharam com trabalhos manuais poderiam atuar como funcionários do rei. Após comprovada essa "limpeza", o candidato faria uma prova para mostrar seu conhecimento em conteúdos jurídicos. Se fosse bem nessa etapa, entraria em uma espécie de lista de espera de nomeação para ocupar o cargo em algum lugar dos domínios portugueses SCHWARTZ, Stuart. Burocracia e sociedade no Brasil colonial, op. cit. p, 81.

${ }^{25}$ Requerimento de José Belarmino Crê, nomeado juiz de fora de Cuiabá, à rainha, D. Maria, em que pede certidão em que constem as provisões passadas a favor de seus antecessores. Ant. a 04/04/1778. AHU, Projeto Resgate-MT. Cd 004, pasta 018, subpasta 001, fotos 0187-0190.

${ }^{26}$ SUBTIL, José. Dicionário dos desembargadores. op. cit. p, 332

${ }^{27}$ BICALHO, Maria Fernanda. A cidade e o império. op. cit. pp. 347-8

${ }^{28}$ SOUSA, Avanete Pereira Poder local, cidade e atividades econômicas. op. cit p, 70.

${ }^{29}$ SCHWARTZ, Stuart. Burocracia e sociedade no Brasil colonial, op. cit. Ver capítulo 13: O abrasileiramento da burocracia, p. 253-254.

${ }^{30}$ MELLO, Isabela de Matos Pereira. Magistrados a serviço do rei: a administração da justiça e os ouvidores gerais na comarca do Rio de Janeiro (1710-1790). Tese (Doutoramento em História), UFF, Niterói, 2013, p. 37.

${ }_{31}$ ALBUEQUERQUE, Vanessa da Silva. Família Gusmão: do colégio jesuíta às idéias ilustradas do século XVIII.

http://www.rj.anpuh.org/resources/rj/Anais/2004/Simposios\%20Tematicos/Vanessa\%20da\%2

OSilva\%20Albuquerque.doc Acesso em: 27/07/2015.

${ }^{32}$ SUBTIL, José. Dicionário dos desembargadores. op. cit. p, 152; ARAÚJO, Renata Malcher. A urbanização do Mato Grosso no século XVIII: discurso e Método. Tese (Doutoramento em História da Arte), FCSH, Universidade Nova de Lisboa, Lisboa, 2000, p. 578.

${ }^{33}$ ROSA, Carlos Alberto. Confidências mineiras na parte mais central da América do Sul. Revista Território e Fronteiras, vol. 1, ano 1, jul-dez 2000, p. 42.

${ }^{34}$ SCHWARTZ, Stuart. Burocracia e sociedade no Brasil colonial, op. cit. p, 29.

${ }^{35}$ Idem. Ibidem, p. 28.

${ }^{36}$ SUBTIL, José. Dicionário dos desembargadores. op. cit. pp, 152-3.

${ }^{37}$ Processo de Antônio Rodrigues Gaioso. Lisboa, ANTT. 05/06/1778. Desembargo do Paço, Leitura de Bacharéis, Letra A, Maço 25, nº 5. 
${ }^{38}$ Carta do juiz de fora da Vila do Cuiabá, José Carlos Pereira, ao governador e capitão general da capitania do Mato Grosso, Luís de Albuquerque Melo Pereira e Cáceres. Vila do Cuiabá, 08/05/1780. Arquivo Público do Mato Grosso. BRAPMT. CVC. JF. CA. Carta 0500, Caixa 010.

${ }^{39}$ Requerimento do bacharel Manuel Fangueiro Frausto, provido juiz de fora do Mato Grosso, ao rei, D. José, em que pede que se dê a sua mulher, Antônia Joaquim Lobato uma mesada de 20 mil réis. Lisboa, 05/04/1755. AHU. Projeto resgate. Cd 03. Pasta 008. Subpasta 001. Fotos 151-154.

${ }^{40}$ Requerimento do bacharel João Batista Duarte, nomeado juiz de fora da Vila de Cuiabá, ao rei, D. José, em que pede para juntar a consulta em ano para a vista de ela conceder-lhe ajuda de custa que é costume praticar. Lisboa, 16/02/1765. AHU. Projeto resgate. Cd 4. Pasta 012. Subpasta 001. Fotos 87-94.

${ }^{41}$ SUBTIL, José. Dicionário dos desembargadores. op. cit. p, 408.

${ }^{42}$ Habilitação de Constantino José Silva Azevedo. Lisboa, 22/11/1773, ANTT . Mesa da Consciência e Ordens, Habilitações para a Ordem de Cristo, letra C, Maço 8, proc. 8.

${ }^{43}$ ALMEIDA, Suely Creusa Cordeiro. As peripécias do magistrado. op. cit. p, 2.

${ }^{44}$ Oficio do governador e capitão general da capitania de Mato Grosso, Antonio Rolim de Moura, ao Secretario da Marinha e Ultramar, Tomé Joaquim da Costa Corte Real, sobre a ordem retirada de todos os padres da companhia, informa também sobre a atuação de Manoel Frangueiro Frausto como juiz de fora, e outros assuntos. Vila Bela, 29/11/1759. AHU. Projeto resgate. Cd 3. Pasta 010. Subpasta 001. Fotos 95-106.

${ }^{45}$ Requerimento do bacharel Manuel Fangueiro Frausto, provido juiz de fora do Mato Grosso, ao rei, D. José, em que pede que se dê a sua mulher, Antônia Joaquim Lobato, uma mesada de 20 mil réis. Lisboa, 05/04/1755. AHU. Projeto resgate. Cd 03. Pasta 008. Subpasta 001. Fotos 151-154.

${ }^{46}$ Oficio do ouvidor de Mato Grosso, Manuel Fangueiro Frausto, ao Secretário da Marinha e Ultramar, Tomé Joaquim da Costa Corte Real, sobre ter tomado posse como ouvidor e se ter extinguido o cargo de juiz de fora, pede para servir como honorífico da beca e acesso à Relação do Porto e 600 mil réis com três mil reis desde o dia de sua posse. Vila Bela, 04/09/1759. AHU, Projeto Resgate-MT. Cd 003, pasta 010, subpasta 001, fotos 088094.

${ }^{47}$ Em um documento de 1781, aproximadamente vinte anos após à atividade de Manuel Fangueiro Frausto, temos a menção de "trezentos e cinquenta oitava e um quarto, que são quatrocentos e vinte mil e trezentos réis". Dessa forma, uma oitava equivalia à 1.200 réis. Portanto, a quantia acumulada pelo juiz de fora foi de 2 contos e 344 réis, enquanto a arrecadação total da capitania foi de dezenove contos e quinhentos réis. Carta de Lourenço Leite Penteado ao juiz de fora da Vila do Cuiabá, Antonio Rodrigues Gaioso. Presídio de Coimbra, 10/10/1781, APMT. BRAPMT. FC. CA. Caixa 001, doc. 0053.

${ }^{48}$ Oficio do ouvidor de Mato Grosso, Manuel Fangueiro Frausto, ao Secretário da Marinha e Ultramar, Tomé Joaquim da Costa Corte Real, sobre ter tomado posse como ouvidor e se ter extinguido o cargo de juiz de fora, pede para servir como honorífico da beca e acesso à Relação do Porto e 600 mil réis com três mil reis desde o dia de sua posse. Vila Bela, 04/09/1759. AHU, Projeto Resgate-MT. Cd 003, pasta 010, subpasta 001, fotos 088094.

${ }^{49}$ Carta do ouvidor Geral do Mato Grosso, Miguel Pereira Pinto, ao rei, D. José, em que tirou residência ao exjuiz de fora da Vila de Cuiabá, Constantino José da Silva Azevedo. Vila de Cuiabá, 04/11/1771. AHU. Projeto resgate - MT. Cd 4. Pasta ,14. Subpasta 003. Fotos 445-446.

${ }^{50}$ Oficio do governador e capitão general da capitania de Mato Grosso, Antonio Rolim de Moura, ao Secretario da Marinha e Ultramar, Tomé Joaquim da Costa Corte Real, sobre a ordem retirada de todos os padres da companhia, informa também sobre a atuação de Manoel Frangueiro Frausto como juiz de fora, e outros assuntos. Vila Bela, 29/11/1759. AHU. Projeto resgate. Cd 3. Pasta 010. Subpasta 001. Fotos 95-106.

${ }^{51}$ Idem.

${ }^{52}$ SCHWARTZ, Stuart. Burocracia e sociedade no Brasil colonial, op. cit., p. 263.

${ }^{53}$ Idem, Ibidem, p. 262.

${ }^{54}$ SOUZA, Laura de Mello e. O Sol e a Sombra: política e administração na América portuguesa do século XVIII. São Paulo: Companhia das Letras, 2006. Ver especialmente o capítulo 5: Teoria e prática do governo colonial: Dom Pedro de Almeida, conde de Assumar.

${ }^{55}$ Processo de Antônio Rodrigues Gaioso. Lisboa, ANTT. 05/06/1778. Desembargo do Paço, Leitura de Bacharéis, Letra A, Maço 25, nº 5; SUBTIL, José. Dicionário dos desembargadores. op. cit. p, 408.

${ }^{56}$ Carta do juiz de fora da Vila do Cuiabá, Luís Manoel de Moura Cabral, ao governador e capitão general da capitania do Mato Grosso João de Albuquerque Mello Pereira e Cáceres. 01/01/1791, Rio de Janeiro. BR APMT. CVC. JF. CA0654, Caixa nº 012.

${ }^{57}$ Habilitação de Constantino José Silva Azevedo. Lisboa, 22/11/1773, ANTT . Mesa da Consciência e Ordens, Habilitações para a Ordem de Cristo, letra C, Maço 8, proc. 8.

${ }^{58}$ Oficio do governador e capitão general da capitania de Mato Grosso, João da Câmara Coutinho ao Secretario da Marinha e Ultramar, Francisco Xavier de Mendonça Furtado sobre a má conduta do juiz de fora da Vila do 
Cuiabá, Constantino José da Silva Azevedo. Vila Bela da Santíssima Trindade, 10/06/1766. Arquivo Histórico Ultramarino. Projeto Resgate Barão do Rio Branco-MT. Cd 004. Pasta 012. Subpasta 001-002. Fotos 177-207.

${ }^{59}$ Maiores conjecturas em relação a essas indicações para a ouvidoria fazem parte da conjuntura da transferência desse cargo para Vila Bela enquanto o juizado de fora se transferiria para a Vila da Cuiabá ver: ALMEIDA, Gustavo Balbueno de. Os juízes de fora e os conflitos de jurisdição na capitania de Mato Grosso (1748-1796). Dissertação (Mestrado em História). UFGD, Dourados, 2012, pp. 30-34.

${ }^{60}$ Decreto de D. Maria a fazer mercê a José Carlos Pereira, ex-juiz de fora da Vila de Cuiabá, e ouvidor interino de Mato Grosso, o lugar de Intendente do ouro de Goiás. AHU, Projeto Resgate. Lisboa, 10/04/1784.

${ }^{61}$ SUBTIL J. Dicionário dos desembargadores, p. 108.

${ }^{62}$ Idem. Ibidem. p, 152-3.

${ }^{63}$ Requerimento do ex-juiz de fora de Cuiabá, Diogo de Toledo Lara Ordonhez, à rainha, [D. Maria], solicitando declaração em que conste os 600 mil réis recebeu-lhe compitão (sic) e que por isso fique sem efeito a fiança que prestou em uma provedoria do Mato Grosso. Ant. a 09/12/1794. AHU, Projeto Resgate-MT. Cd 006, pasta 027, subpasta 002, fotos 235-263.

${ }^{64}$ ROSA, Carlos Alberto. A Vila Real do Senhor Bom Jesus do Cuiabá - Vida urbana em Mato Grosso no século XVIII (1727 - 1808). Tese (Doutorado em História). USP, São Paulo, 1996, p.155.

${ }^{65}$ ARAÚJO, Renata Malcher. A urbanização do Mato Grosso no século XVIII. op. cit. p, 578

${ }^{66}$ SUBTIL J. Dicionário dos desembargadores, p. 408

${ }^{67}$ Oficio do governador e capitão general da capitania de Mato Grosso, João Pedro da Câmara, ao secretario da marinha e ultramar, Francisco Xavier de Mendonça Furtado, sobre o procedimento do juiz de fora da Vila de Cuiabá, Constantino José da Silva Azevedo, que deve receber castigo agora que deve se retirar. Nossa Senhora da Conceição, 28/11/1766. AHU. Projeto resgate. Cd 4. Pasta 12. Subpasta 002. Fotos 290-293.

${ }^{68}$ Habilitação de Constantino José Silva Azevedo. Lisboa, 22/11/1773, ANTT . Mesa da Consciência e Ordens, Habilitações para a Ordem de Cristo, letra C, Maço 8, proc. 8.

${ }^{69}$ Os documentos referentes ao período em que esteve à frente do juizado de fora da Cuiabá no Arquivo Histórico Ultramarino são poucos, mesmo tendo ele permanecido no cargo por dez anos, e suas correspondências contidas no Arquivo Público de Mato Grosso não foram levantadas por nós, o que significa que não nos aprofundaremos nas particularidades do mandato desse oficial.

${ }^{70}$ ROSA, Carlos Alberto. A Vila Real do Senhor Bom Jesus do Cuiabá. op. cit. p, 252

${ }^{71}$ MELLO, Isabela de Matos Pereira. Magistrados a serviço do rei: a administração da justiça e os ouvidores gerais na comarca do Rio de Janeiro (1710-1790). Tese (Doutoramento em História), UFF, Niterói, 2013, p. 202.

${ }^{72}$ Requerimento do juiz de fora da Vila do Cuiabá, Constantino José da Silva Azevedo ao rei, D. José, em que pede lhe seja tirada a residência. Vila do Cuiabá, ant. a 03/08/1770. AHU, Projeto Resgate-MT. CD 004, Pasta, 014, Subpasta 001, Fotos 145-147; Carta do ouvidor geral do Mato Grosso, Miguel Pereira Pinto, ao rei, D. José, em que tirou residência ao ex-juiz de fora da Vila do Cuiabá, Constantino José da Silva Azevedo. Vila de Cuiabá, 04/11/1771. AHU, Projeto Resgate-MT. CD 004, pasta 014, subpasta 003, fotos 444-445.

${ }^{73}$ PIJNING, Ernst. Contrabando, ilegalidade e medidas políticas no Rio de Janeiro do século XVIII. Revista Brasileira de História. São Paulo: ANPUH/ Humanitas Publicações, vol. 21, no 42, pp. 407-8. Disponível em: www.redalyc.uaemex.mex/pdf/263/26304207.pdf. Acesso dia 07/05/2015.

${ }^{74}$ Apesar de longo, infelizmente o documento encontra-se em péssimo estado, o que o torna ilegível em sua grande maioria, e nos impossibilita de analisar a atuação desse oficial. Oficio do governador e capitão general da capitania de Mato Grosso, João da Câmara Coutinho ao Secretario da Marinha e Ultramar, Francisco Xavier de Mendonça Furtado sobre a má conduta do juiz de fora da Vila do Cuiabá, Constantino José da Silva Azevedo. Vila Bela, 10/02/1766. AHU. Projeto resgate. Cd 4. Pasta 012. Subpasta 001-002. Fotos 177-207.

${ }^{75}$ Carta do governador e capitão general da capitania de Mato Grosso, João Pedro da Câmara, ao rei, D. José, em que informa que deu posse a João Batista Duarte no lugar de juiz de fora na Vila do Cuiabá. Nossa Senhora da Conceição, 01/08/1767. AHU, Projeto Resgate - MT. CD 004, pasta 012, subpasta 002, fotos 347-350.

${ }^{76}$ MARCELO, Cristiane Maria. Os embates de um juiz de fora: Balthazar da Silva Lisboa na capitania do Rio de Janeiro (1787-1786). Dissertação (Mestrado em História). UFF, Niterói, 2010, p. 37.

${ }^{77}$ Carta do governador e capitão general da capitania de Mato Grosso, João Pedro da Câmara, ao rei, D. José, em que informa que deu posse a João Batista Duarte no lugar de juiz de fora na Vila do Cuiabá. Nossa Senhora da Conceição, 01/08/1767. AHU, Projeto Resgate - MT. CD 004, pasta 012, subpasta 002, fotos 347-350.

${ }^{78}$ SOUSA, Avanete Pereira Poder local, cidade e atividades econômicas. op. cit p, 78.

${ }^{79}$ Carta dos vereadores da Câmara da Vila de Cuiabá à rainha, D. Maria, em que pedem a recondução de José Carlos Pereira ao cargo de juiz de fora. Vila de Cuiabá. 14/02/1778. AHU. Projeto resgate-MT. Cd 4. Pasta 18. Subpasta 001. Fotos 151-163; Carta do povo e da câmara da Vila do Cuiabá à rainha, D. Maria, em que fazem elogios ao juiz de fora, Diogo de Toledo Lara Ordonhez, e pedem sua conservação naquele lugar. Vila do Cuiabá, 12/08/1787. AHU, Projeto Resgate-MT. Cd 005, pasta 023, subpasta 003, fotos 502-513; ROSA, Carlos Alberto. Confidências mineiras na parte mais central da América do Sul. op. cit, p. 50. 


\section{Referências bibliograficas}

ALBUEQUERQUE, Vanessa da Silva. Família Gusmão: do colégio jesuíta às idéias ilustradas do século XVIII.. http://www.rj.anpuh.org/resources/rj/Anais/2004/Simposios\%20Tematicos/Vanessa\%20da\%2 0Silva\%20Albuquerque.doc Acesso em: 27/07/2015.

ALMEIDA, Gustavo Balbueno de. Os juízes de fora e os conflitos de jurisdição na capitania de Mato Grosso (1748-1796). Dissertação (Mestrado em História). UFGD, Dourados, 2012.

ALMEIDA, Suely Creusa Cordeiro. As peripécias do magistrado: Juízes de fora e um cotidiano nada tranquilo entre Recife e Olinda. Mneme - Revista de Humanidades - UFRN. Vol. 9, n24, set/out 2008. Disponível em: www.cerescaico.ufrn.br/mneme/anais. Acesso em: 21/02/2011.

ARAÚJO, Renata Malcher. A urbanização do Mato Grosso no século XVIII: discurso e Método. Tese (Doutoramento em História da Arte), FCSH, Universidade Nova de Lisboa, Lisboa, 2000.

AMARAL, Luís; MATOS, Lourenço Correia de. Leitura de bacharéis - Índice dos processos. Lisboa: Guarda-mor, 2007[?].

BICALHO, Maria Fernanda. A cidade e o império - O Rio de Janeiro no séc. XVIII. Rio de Janeiro. Civilização Brasileira, 2003.

. As câmaras ultramarinas e o governo do Império. In: BICALHO, Maria Fernanda; FRAGOSO, João; Gouvêa, Maria de Fátima (Orgs.). O antigo regime nos trópicos: a dinâmica imperial portuguesa (séculos XVI-XVII). Rio de Janeiro. Civilização brasileira, 2010.

As câmaras municipais no Império português: o exemplo do Rio de Janeiro. Revista Brasileira de História, vol. 18. $\mathrm{n}^{\circ}$ 36. São Paulo, 1998. Disponível em: http://www.scielo.br/scielo.php?pid=S0102-01881998000200011\&script=sci_arttext.

Acessado dia: 13\05\2015.

BOXER, Charles. O Império Ultramarino Português (1415-1825). São Paulo: Companhia das letras, $3^{\circ}$ reimpressão 2002.

CAMARINHAS, Nuno. Juizes e administração da justiça no Antigo Regime. Portugal e o império colonial, séculos XVII e XVIII. Lousã: Fundação Calouste Gulbekian, 2010.

FAORO, Raymundo. Os donos do poder. Formação do patronato político brasileiro. $2^{\circ}$ ed. São Paulo: Ed. Globo, 1975.

HESPANHA, Antônio Manuel. Às vésperas do Leviathan. Instituições e poder político, Portugal, séc. XVII. Coimbra: Livraria Almedina, 1994.

HESPANHA, Antônio Manuel; XAVIER, Ângelo Barreto. A representação da sociedade e do poder. In: HESPANHA, Antônio Manuel (cord.); MATTOSO, José (org.) História de Portugal: O Antigo Regime. Lisboa, Editorial Estampa, 1993, vol 4.

JESUS, Nauk Maria de. A administração da justiça: Ouvidores e regentes na fronteira oeste da América portuguesa. In GUEDES, Roberto (org.) Dinâmica Imperial no Antigo Regime Português. Escravidão, governos, fronteiras, poderes, legados. Rio de Janeiro: MAUAD X, 2011.

Na trama dos conflitos: a administração na fronteira oeste da América portuguesa(1719-1778). 2006. 439 f. Tese (Doutoramento em História). UFF, Rio de Janeiro. 
LACERDA, Leila Borges de. Donativo Voluntário; In: JESUS, Naul Maria de. (org.). Dicionário de História de Mato Grosso, período colonial. Cuiabá, ed. Carlini Caniato, 2011. LEVERGER, Augusto de. Apontamentos cronológicos da província de Mato Grosso. Cuiabá:IHGMT, 2001.

MARCELO, Cristiane Maria. Os embates de um juiz de fora: Balthazar da Silva Lisboa na capitania do Rio de Janeiro (1787-1786). Dissertação (Mestrado em História). UFF, Niterói, 2010.

MELLO, Isabela de Matos Pereira. Magistrados a serviço do rei: a administração da justiça e os ouvidores gerais na comarca do Rio de Janeiro (1710-1790). Tese (Doutoramento em História), UFF, Niterói, 2013.

MONTEIRO, Nuno Gonçalo. As comunidades e os concelhos. In: HESPANHA, Antonio. M; MATTOSO, José. História de Portugal - o Antigo Regime (1620-1807), volume IV. Lisboa: Editorial Estampa, 1993.

PIJNING, Ernst. Contrabando, ilegalidade e medidas políticas no Rio de Janeiro do século XVIII. Revista Brasileira de História. São Paulo: ANPUH/ Humanitas Publicações, vol. 21, $\mathrm{n}^{\mathrm{o}}$ 42, Disponível em: www.redalyc.uaemex.mex/pdf/263/26304207.pdf. Acesso dia 07/05/2015.

PEGORARO, Jonas Wilson. Ouvidores régios e centralização jurídico-administrativo na América portuguesa: a comarca de Paranaguá (1723-1812).. Dissertação (Mestrado em História). UFPR, Curitiba, 2007.

PRADO JR. Caio. Formação do Brasil Contemporâneo. 17ed. São Paulo: Brasiliense, 1981. PUNTONI, Pedro. "Como coração no meio do corpo": Salvador, capital do Estado do Brasil. In: BICALHO, Maria Fernanda B (Org.); FURTADO, Júnia Ferreira (Org.); SOUZA, Laura de. Mello e. (Org.). O governo dos povos. São Paulo: Alameda, 2009.

ROSA, Carlos Alberto. A Vila Real do Senhor Bom Jesus do Cuiabá - Vida urbana em Mato Grosso no século XVIII (1727 - 1808). Tese (Doutorado em História). USP, São Paulo, 1996. . Confidências mineiras na parte mais central da América do Sul. Revista Território e Fronteiras, vol. 1, ano 1, jul-dez 2000.

SCHWARTZ, S. B. Burocracia e sociedade no Brasil colonial, São Paulo: Companhia das letras, 2011.

SOUSA, Avanete Pereira Poder local, cidade e atividades econômicas. (Bahia, século XVIII). Tese (Doutorado em História), PPGHE, Dep. de História, FFLCH, USP, São Paulo, 2003.

SOUZA, Débora Cazelato de. Administração e poder local: a câmara de Mariana e seus juízes de fora (1730-1777). Dissertação (Mestrado em História). UFOP, Mariana, 2011.

SOUZA, Laura de Mello e. Desclassificados do ouro: a pobreza mineira no século XVIII. $3^{\circ}$ ed. Rio de Janeiro: Graal, 1986.

- O Sol e a Sombra: política e administração na América portuguesa do século XVIII. São Paulo: Companhia das Letras, 2006.

STONE, Lawrence. Prosopografia. In.: Revista de Sociologia e Política. V.19, n 39. Curitiba: Junho 2011. Disponível em:

http://www.scielo.br/scielo.php?pid=S0104-44782011000200009\&script=sci_arttext. Acessado dia 06/11/2015.

SUBTIL, José. Dicionário dos desembargadores (1640-1834). Lisboa: EDIUAL, 2010. 